\title{
A STATISTICAL APPROACH TO THE DETERMINATION OF THE MAJOR CONTRIBUTING ANTHROPOMETRIC PARAMETER(S) FOR REGIONAL VARIATION IN BODY MASS INDEX IN COASTAL AND PLAIN REGIONS OF INDIA: A PILOT COHORT STUDY
}

\author{
J. P. Verma ${ }^{1}$, Harinder Jaseja², Nikolay Boyadjiev ${ }^{3}$, \\ Priti Gurjar $^{1}$, Amey Bhojane ${ }^{1}$, Ajeet Singh ${ }^{1}$ \\ 1. Lakshmibai National Institute of Physical Education, Gwalior, India \\ 2. G R Medical College, Gwalior, India \\ 3. Medical University Plovdiv, Bulgaria
}

\begin{abstract}
An estimate of body mass index (BMI) is a convenient technique to determine a healthy weight in accordance with height and is based on certain anthropometric parameters. This study was undertaken to statistically analyze the differential significance of anthropometric parameters in contributing to regional and age variation in BMI in a cohort population. The study population comprised of 101 school teachers from Mumbai (coastal) and Gwalior (plains) regions of both sex (males=76) and (females=25). The data on age, waist circumference and hip circumference was obtained and subjected to regression analysis using the IBM SPSS version 22 software. In general, the results show that, waist in males and hip circumference in females is the single most important parameter in estimating the BMI. However, by considering all the three parameters i.e. age, waist and hip circumferences, the accuracy of BMI estimation can be enhanced both in males and females. The results exhibit a significant effect of regional influence but marginal influence of age in estimating the BMI.

A definite and interesting difference in the contribution of anthropometric parameters in the regional variation of BMI was detected. The observations strongly suggest development of region-wise as well as age-wise BMI estimation models.
\end{abstract}

Key words: BMI, regression analysis, regional influence on BMI, anthropometric

\section{INTRODUCTION}

Body mass index (BMI) is an indirectly calculated estimate of body fat based on weight and height used to help determine whether a person is in a state of healthy or unhealthy weight. A high BMI usually indicates excessive fat in the body; likewise, a low BMI is indicative of decreased fat. A high BMI is believed to be generally associated with serious conditions, such as heart disease, high blood pressure, diabetes and metabolic abnormalities (Sinha et al., 2002; Marcovecchio et al.; 2005, Cali et al.; 2007; Berenson, 2005).
Weight-related concerns and body dissatisfaction are major influential factors in the predisposition to eating disorders and psychological disturbances like depression (Stice and Shaw, 2002; Neumark-Sztainer, 2006; Ackard and Croll, 2002; Stice and Bearman, 2001; Johnson and Wardle, 2005).

A very low BMI can also cause health problems like osteoporosis, decreased immune function and nutritional deficiencies.

WHO also has recommended classifications of bodyweight based on body-mass index 
(BMI), the deviation from the normal range of which can be associated with increased risk of some non-communicable diseases (WHO, 1995; WHO, 2000). However, a few studies indicate that body fat, not BMI, is a more reliable indicator of health risks.

Although BMI is useful in mass screening of a population for body weight related problems, it has definite limitations. It may overestimate the amount of body fat in athletes and other people with very muscular bodies; on the other hand, it may also underestimate the amount of body fat in older adults and other people who have for various reasons lost muscle mass.

In recent times, researchers have raised doubts and concerns over the accuracy of BMI for measuring body weight claiming that it cannot distinguish between fat and muscle mass; furthermore, it also fails to provide clear distinction among the different types of fat that have differential beneficial and metabolic effects in the body. Several findings suggested that BMI is a flawed measure as it does not correctly identify individuals with excess body fat due to its inability to differentiate fat and fat-free mass and it does not account for the effect of age and ethnicity on body fat distribution (Fogelholm, 2010; Romero-Corral et al., 2008; WHO, 2000; Deurenberg et al.,1998; Welborn and Dhaliwal, 2011).

The study published in PLOS by Wang et al. (2018) reported significant difference in analysis of BMI and body weight perception and the consistency of BMI and body weight perception was poor.

Generally, the range of a healthy BMI is 18.5 to 24.9. However, for Indians, it is found that even people with lower BMI than 25 are vulnerable to health risks especially diabetes; hence, the healthy BMI cut off value has been lowered to 23, the rationale behind it being that Asian people possess more fat content than non-Asians and the distribution of fat also differs in Asians as compared to that in the Western population.

Ahmed et al. (2016) reported that the waist circumference (WC) also plays an important role in measuring obesity; hence, both BMI and $\mathrm{WC}$ are important for measuring obesity in the Indian population. Abdominal obesity as determined by increased WC is an established risk factor for metabolic syndrome, diabetes mellitus and cardiovascular disease in adults (Zimmet et al., 2007). In one study (Kavaric et al., 2015), it was found that WC correlated better than BMI with cardio-metabolic markers in healthy normal weight and overweight adolescents. Madeshiya et al also observed BMI, WC, hip circumference (HC) and waist-hip ratio (WHR) as independent markers for obesity, suggesting that only one of these measures need to be obtained for clinical and research purpose (Madeshiya et al., 2017). Therefore, it is in the absence of a more rapid and cost-effective means of estimation of body fat that BMI is viewed as the best option even today.

Data available on regional variation of BMI in India is limited. This study was undertaken with the objective of determining major contributing anthropometric parameters in regional difference(s) in BMI in a cohort of male and female school teachers.

\section{MATERIALS AND METHODS}

The study population comprised of 101 school teachers with nearly similar lifestyle and dietary habits. There were 76 males aged $22-60$ years (mean $\pm \mathrm{SD}=46.66 \pm 8.79$ years) and 25 females aged 30-56 years (mean $\pm \mathrm{SD}=46.96 \pm 8.52$ years $)$. The participants were from Mumbai (coastal) and Gwalior (plains) regions.

The subjects' data on age, waist circumference, hip circumference and waist to hip ratio were collected and subjected to regression analysis using the IBM SPSS version 22 software. 


\section{RESULTS}

The study was targeted at the school teachers considering that they fairly represent a well-educated section of the society and are in an authentic position to systemically educate and disseminate knowledge and importance of BMI to students (growing youth of the society) in a divergent manner. The data were analyzed to investigate the following four research issues:

Possible identification of a single parameter that is strongly associated with BMI assessment in males and females separately.

Possible maximization of BMI estimation by developing models in males and females separately.

Regional specificity of BMI estimation in both genders.
Cluster age category specificity of BMI estimation in both genders.

In order to address the above four issues, the data were analyzed with regression analysis (Verma, 2016). All the models discussed in Table 1 to Table 4 were found to be significant at $5 \%$ level. Table 1 shows the coefficient of determination $\left(\mathrm{R}^{2}\right)$ which was obtained by simple regression in which three independent variables namely age, waist and hip circumferences were investigated. It can be seen that the waist accounts for $46.2 \%$ variability in BMI in the male category; whereas, in females $70.6 \%$ variability in BMI is accounted for by the hip circumference. Thus, waist circumference in males and hip circumference in females are the single most important parameters in estimating BMI.

Table 1. Single most important parameter in estimating BMI

\begin{tabular}{ccc}
\hline Gender & Variable & $\begin{array}{c}\text { Coefficient of Determination } \\
\left(\mathbf{R}^{2}\right)\end{array}$ \\
\hline Male & Waist & 0.462 \\
\hline Female & Hip & 0.706 \\
\hline
\end{tabular}

Dependent variable: $B M I$

The results of multiple regression for estimating BMI in males and females are shown in Table 2. In males, besides waist circumference, if age and hip circumference are also included in the model, $51.6 \%$ variability is accounted for in the BMI estimation instead of $46.2 \%$ when only waist circumference is

Table 2. Model parameters in estimating BMI

\begin{tabular}{ccc}
\hline Gender & Model Parameters & $\begin{array}{c}\text { Coefficient of Determination } \\
\left(\mathbf{R}^{\mathbf{2}}\right)\end{array}$ \\
\hline Male & age, waist, hip & 0.516 \\
\hline Female & age, waist, hip & 0.717 \\
\hline Dependent variable: $B M I$
\end{tabular}

taken. Similarly, in females, inclusion of age and waist circumference with hip circumference enhances accountability of $71.7 \%$ variability in BMI. Thus, BMI can be estimated more accurately by inclusion of age, waist and hip circumferences in comparison to only one variable. 
In order to see the impact of regional influence (coastal and plains) in estimating BMI, the regression analysis was performed region wise in males and females separately the results of which are shown in Table 3 . It can be seen from this table that in Mumbai three parameters (age, waist and hip circumference) accounts for $76.5 \%$ variability in BMI in comparison to only $41.7 \%$ in Gwalior in the male category.

Table 3. Effect of Regional influence in estimating BMI

\begin{tabular}{cccc}
\hline Gender & Region & Model Parameters & $\begin{array}{c}\text { Coefficient of Determination } \\
\left(\mathbf{R}^{2} \mathbf{)}\right.\end{array}$ \\
\hline \multirow{2}{*}{ Male } & Gwalior & age, waist, hip & 0.417 \\
\cline { 2 - 4 } & Mumbai & age, waist, hip & 0.765 \\
\hline \multirow{2}{*}{ Female } & Gwalior & age, waist, hip & 0.894 \\
\cline { 2 - 4 } & Mumbai & age, waist, hip & 0.572 \\
\hline
\end{tabular}

Dependent variable: $B M I$

To observe the impact of age in estimating BMI, regression analysis was performed first by taking all the subjects (age varying from 22 to 60 years) and then restricting with the subjects in 35-55 years age category. The age category $35-55$ years was chosen because of less energy imbalance in comparison to the age category 22 to 60 years. All models in male and female categories are shown in Table 4. Each model included the same three parameters namely age, waist and hip circumference but different levels of predictability. The coefficient of determination $\left(\mathrm{R}^{2}\right)$ indicates the percentage variability in the BMI ex- plained by the independent variables selected in the model. It can be seen from the Table 4 that in the male category (35-55 years), the model comprising three independent variables namely age, waist and hip circumferences accounts for $67.2 \%$ variability in comparison to $51.6 \%$ when all the subjects were taken (22-60 years). On the other hand, in female category the same three variables in the model accounts for $71.7 \%$ variability when all the subjects were taken (22-60) in comparison to $70.9 \%$ variability when subjects were taken in $35-55$ years weight category.

Table 4. Effect of Age in estimating BMI

\begin{tabular}{cccc}
\hline Gender & Age category & Model Parameters & $\begin{array}{c}\text { Coefficient of Determination } \\
\left(\mathbf{R}^{2} \mathbf{)}\right.\end{array}$ \\
\hline \multirow{2}{*}{ Male } & $22-60 \mathrm{yrs}$ & age, waist, hip & 0.516 \\
\cline { 2 - 4 } & $35-55 \mathrm{yrs}$ & age, waist, hip & 0.672 \\
\hline \multirow{2}{*}{ Female } & $22-60 \mathrm{yrs}$ & age, waist, hip & 0.717 \\
\cline { 2 - 4 } & $35-55 \mathrm{yrs}$ & age, waist, hip & 0.709 \\
\hline
\end{tabular}

Dependent variable: $B M I$ 


\section{DISCUSSION}

The analysis of the results shows that the estimation of BMI in Mumbai region is more reliable in comparison to Gwalior as far as males are concerned. However, this trend is reversed in the female category where more variability in BMI is accounted for in the Gwalior region $(89.4 \%)$ in comparison to that in Mumbai (57.2\%).BMI can be viewed as an important factor for health as it gives an indication of desirable weight in accordance with the height and a possible carriage of risk factor(s) for certain diseases mentioned in earlier section; it can, therefore, operate as an alert signal for pre-emptive measures required to be taken in the form of lifestyle and dietary changes to ward off the health risks.

Although BMI is an easy and popular method of identifying the weight of a person, it does have definite limitations as it does not take the body fat measurement into consideration and suitable correction for men and women that are known to possess differences in body frame and muscular build up, and lastly BMI cannot directly indicate any health disease.

It can be questioned why we have tried to estimate the BMI in different regions and age categories; the fact that the estimation of BMI is more accurate in certain region and age categories suggests that the formula of BMI may be modified region-wise and age-wise if a similar trend is observed in larger studies.

\section{CONCLUSION}

The study shows that there is a differential contribution of various anthropometric parameters for the BMI estimates in male and female participants as well as its regional variation. This small study does possess the potential to stimulate larger well-designed retrospective and prospective studies on BMI and its gender and regional variation across the Indian peninsula that incorporates extensively diversified regional characteristics. The results of the present study should be viewed under the limitation that the small number of subjects was taken in this pilot study. However, to our knowledge, this is one of the very few studies that have been attempted to focus predominantly on statistical analysis of the major contributing anthropometric parameters responsible for BMI and its regional variation in India.

\section{REFERENCES}

Ackard DM, Croll JK, Kearney-Cooke A. (2002). Dieting frequency among college females: association with disordered eating, body image, and related psychological problems. J Psychosom Res.;52(3):129-136.

Ahmad Norfazilah, Adam Samia Ibrahim Mohamed, Nawi Azmawati Mohammed, Hassan Mohd Rohaizat, and Ghazi1Hasanain Faisal. (2016). Abdominal Obesity Indicators: Waist Circumference or Waist-to-hip Ratio in Malaysian Adults Population. Int J Prev Med. 2016; 7: 82. doi: 10.4103/2008-7802.183654

Berenson GS. (2005). Obesity- a critical issue in preventive cardiology: The Bogalusa Heart study. PrevCardiol; 8:234-241.

Cali AM., Zern TL., Taksali SE. (2007). Intrahepatic fat accumulation and alterations in lipoprotein composition in obese adolescents: A perfect proatherogenic state. Diabetes Care.;30:3093-3098.

Deurenberg P, Yap M, van Staveren WA. (1998). Body mass index and percent body fat: a meta-analysis among different ethnic groups. Int J Obes; 22: 1164-1171.

Fogelholm M. (2010). Physical activity, fitness and fatness: relations to mortality, morbidity and disease risk factors. A systematic review. Obes Rev; 11: 202-221.

Johnson F., Wardle J. (2005). Dietary restraint, body dissatisfaction, and psychological distress: a prospective analysis. J Abnorm Psychol.;114(1):119-125.

Kavaric N., Klisic A., Soldatovic I., Bjelakovic B. (2015). Can Waist Circumference 
Be a Reliable Anthropometric Parameter in Healthy Normal Weight and Overweight Adolescents? Iran J Public Health.;44(6):883-884.

Madeshiya AK, Singh S., Dwivedi S., Krishna A., Verma DK. (2017). Body mass index, waist circumference and hip circumference are independent predictors of obesity. Indian Journal PhysiolPharmacol; 61(2):88-92.

Marcovecchio M., Mohn A., Chiarelli F. (2005). Type 2 diabetes mellitus in children and adolescents. $J$ Endocrinol Invest.;28:853-863.

Neumark-Sztainer D., Wall M, Guo J., Story M., Haines J, Eisenberg M. (2006). Obesity, disordered eating, and eating disorders in a longitudinal study of adolescents: how do dieters fare 5 years later? $\mathrm{J} \mathrm{Am} \mathrm{Diet}$ Assoc.;106(4):559-568.

Romero-Corral A., Somers VK., SierraJohnson J. (2008). Accuracy of body mass index in diagnosing obesity in the adult general population. Int J Obes; 32: 959-966.

Sinha R., Fisch G., Teague B. (2002). Prevalence of impaired glucose tolerance among children and adolescents with marked obesity. N Engl J Med.; 346:802-810.

Stice E., Bearman SK. (2001). Bodyimage and eating disturbances prospectively predict increases in depressive symptoms in adolescent girls: a growth curve analysis. Dev. Psychol:;37(5):597-607.

Stice E., Shaw HE. (2002). Role of body dissatisfaction in the onset and maintenance of eating pathology: a synthesis of research findings. J Psychosom Res.;53(5):985-993.

Verma JP. (2016). Sports Research with Analytical Solution using SPSS. Wiley, USA

Wang Y., Liu H., Wu F., Yang X., Yue M., Pang Y., et al. (2018) The association between BMI and body weight perception among children and adolescents in Jilin City, China. PLoS ONE 13(3): e0194237. https://doi. org/10.1371/journal.pone.0194237

Welborn TA., Dhaliwal SS., (2011). Being correct about obesity. Med J Aust; 194: 429-430.

WHO. Obesity: preventing and managing the global epidemic. Report on a WHO Consultation on Obesity, Geneva, 3-5 June 1997. WHO/NUT/NCD/98.1. Technical Report Series Number 894. Geneva: World Health Organization, 2000.

WHO. Physical status: the use and interpretation of anthropometry. Report of a WHO Expert Consultation. WHO Technical Report Series Number 854. Geneva: World Health Organization, 1995.

World Health Organization. Obesity: preventing and managing the global epidemic. Report of a WHO consultation. World Health Organ Tech Rep Ser: WHO, 2000.

Zimmet P., Alberti K., George MM. (2007). IDF Consensus Group. The metabolic syndrome in children and adolescents - an IDF consensus report. Pediatr Diabetes. 2007; 8:299-306.

\section{Corresponding author:}

J.P. Verma

Lakshmibai National University of Physical Education

Department of Sport Psychology HN 73 LNIPE Mela Road Shakti Nagar, Gwalior, MP 474002, India

E-mail: vermajprakash@gmail.com 